\title{
RADIANT IGNITION STUDIES OF AMMONIUM PERCHLORATE BASED PROPELLANTS
}

\author{
A. I. Atwood, K. P. Ford, D. T. Bui, P. O. Curran, \\ and T. Lyle
}

This paper presents an overview of ammonium perchlorate (AP) based propellant ignitability. $\mathrm{A} \mathrm{CO}_{2}$ laser provided the radiant energy source. Neat AP ignition was performed on both production grade and high purity AP. The material was difficult to ignite under the conditions. Five nonmetallized and sixteen metallized AP based formulations were used to examine the effects of particle size, binder type, additives, and coarse-to-fine ratio $(\mathrm{C} / \mathrm{F})$ on propellant ignitability.

\section{INTRODUCTION}

Every combustion process begins with ignition. It must occur reliably in order for a rocket motor to function successfully, and it should be prevented if an unplanned event occurs. With the current interest in insensitive munitions (IM), the relationship between propellant ignitability and hazards response is gaining increased scrutiny.

Ammonium perchlorate is widely used throughout the propulsion industry as an oxidizer in solid rocket propellants. Ammonium perchlorate based rocket propellant formulations are used in a majority of the U.S. tactical missiles, and it is a major component in the Space Shuttle solid booster motors. It is well known that AP-based propellants are easier to ignite than either double-base or nitramine-based composite propellants [1]; however, not all AP-based propellants have the same ignition characteristics.

A contributing factor to the susceptibility of a solid rocket motor to inadvertent ignition has been attributed to what Caveny and Summerfield refer to as propellant flammability [2]. This includes:

(i) propellant ignitability, which in this case is the exothermic propellant response with application of an external heat source;

(ii) flame retention, or the ability of the propellant to self-sustain upon removal of the external heat flux; and 
(iii) flame spreading, or the ability for propellant adjacent to the ignition site to become ignited [3].

The current experimental work seeks to address the combination of what the authors refer to as ignitability and flame retention, recognizing that flame spread is geometry-dependent and not a characteristic of a given propellant formulation. Propellant ignitability, flame retention, and spreading are strongly coupled with respect to solid rocket motor performance.

\section{BACKGROUND}

In this study, propellant ignitability is considered as not just a process, but the successful completion of the process resulting in steady state combustion [4]. Propellant ignitability is illustrated in the general log-time vs. log-flux plot of Fig. 1.

If a thermal flux level is selected (indicated by the dashed line) as time increases, first, there is a period of inert heating. If the external flux is removed at that point, there is no apparent change in the sample but there is heating of the sample and the formation of a thermal profile at the surface of the propellant. As time increases (indicated by the first black line), mildly exothermic reactions begin to occur, the sample will begin to gasify and light will be generated (measured by a photo diode in this experiment). If the external energy flux is removed, the sample may not continue to burn. It is not until thermal exposure exceeds the second solid line, referred to as the go/no-go (GNG) igni-

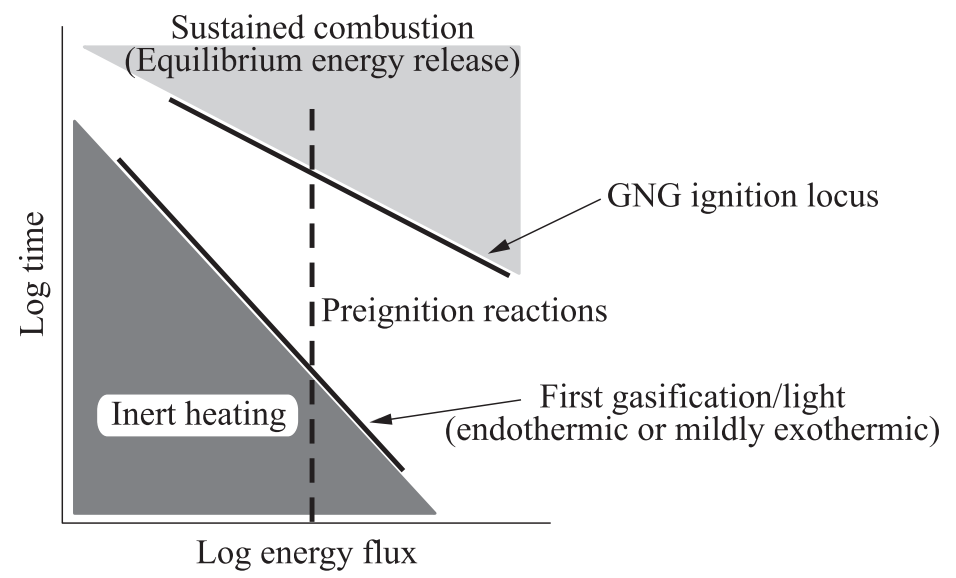

Figure 1 Idealized log-flux vs. log-time plot illustrating propellant ignitability. Location of the lines (and hence energy release) is dependent on many variables 


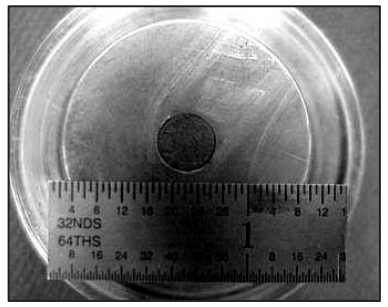

(a)

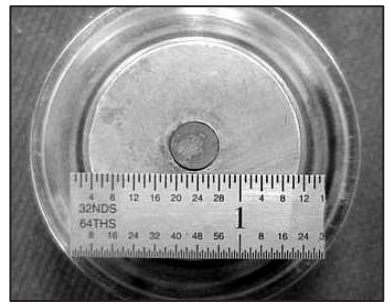

(b)

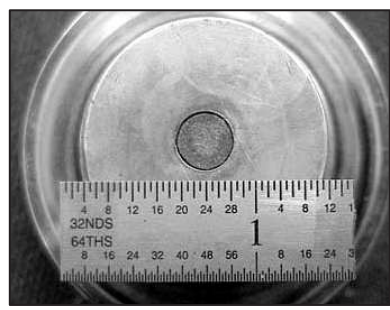

(c)

Figure 2 Example of propellant after subjection to thermal flux exposure: (a) prior to $\mathrm{FL} ;(b)$ at $\mathrm{FL}$; and $(c)$ prior to $\mathrm{GNG}$

tion locus, that the material will continue to burn if the external flux is removed. The thermal profile has been established and the flame is sufficiently stable to sustain reaction without the external stimulus at this point. The relationship between the two lines (first light (FL) / gasification and GNG) is dependent on many variables including pressure, flux level, and formulation type.

The photos in Fig. 2 of propellant samples that have been exposed at $837 \mathrm{~W} / \mathrm{cm}^{2}\left(200 \mathrm{cal} /\left(\mathrm{cm}^{2} \mathrm{~s}\right)\right)$ for various times illustrate the regions of the ignition plot. Sample $2 a$ has been exposed for a time less than that defined by the FL / gasification line. No visible changes to the sample surface can be detected. Sample $2 b$ has been exposed for a time representing the FL/gasification line, and Sample $2 c$ has been exposed for a time slightly less that those defined by the GNG point. Definitions that will be used in this paper include: FL or first gasification, which is sometimes referred to as ignitability or ignition delay; and GNG or complete ignition, which is closer to the point of flame retention referred to previously. The time between FL and GNG has been referred to as ignition delay by these authors, or the preignition zone, but for clarity will be referred to in this paper as the precombustion zone.

This paper examines the effects of pressure and thermal flux on FL and GNG times for various AP-based propellants. Solids loading, oxidizer and metal fuel particle size, binder type, and the introduction of additives were examined with respect to propellant ignitability.

\section{EXPERIMENT}

The ignitability testing described in this paper was performed using a radiant energy experiment. The radiant ignition experiment was not intended to simulate ignition of a solid rocket motor as it lacks the convective and conductive components found in a propulsion system. The experiment does provide a relatively 
Ignition apparatus

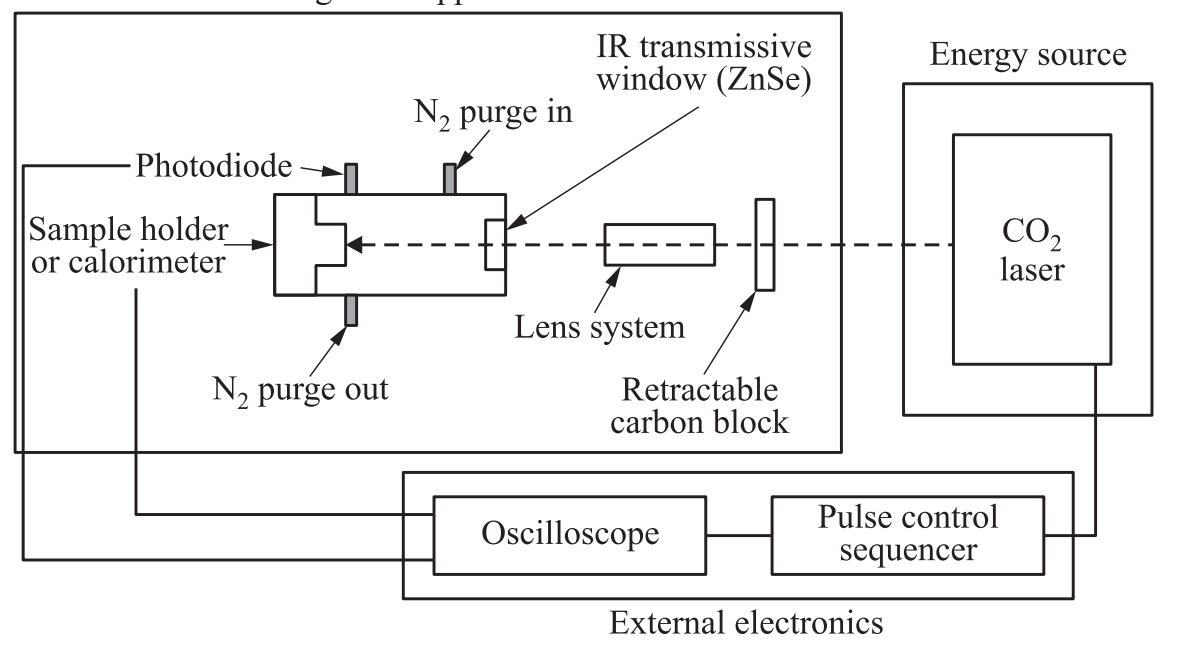

Figure $3 \quad \mathrm{CO}_{2}$ laser ignition system

inexpensive and rapid test with a reproducible thermal flux that can be used to characterize various propellant formulations. The data presented were generated on the same instrumentation with several operators over a 20 -year period.

A schematic of the NAWCWD* radiant ignition system is shown in Fig. 3 . The system is composed of three main components: the energy source, external electronics, and ignition apparatus. The energy source consists of a Photon Sources Model $300 \mathrm{CO}_{2}$ laser. The laser is average rated at $450 \mathrm{~W}$ at a wavelength of $10.6 \mu \mathrm{m}$. The external electronics provide pulse control and record test data. The ignition apparatus consists of the combustion chamber with sample holder, lens system, and chopper wheel. Laser light passes through a long, focallength lens system to increase overall beam diameter. The chopper, located at the focal point of the lens system, is used to decrease the effects of laser rise time at short exposure times. The laser beam enters the combustion chamber through a zinc selenide ( $\mathrm{ZnSe}$ ) window and strikes the propellant surface. First light/gasification is detected by a photodiode sensitive only to light in the visible wavelength region positioned so that the optical axis is aligned parallel with, and approximately $1.6 \mathrm{~mm}$ above, the sample surface. A digital oscilloscope is used to measure the length of laser pulse, FL photodiode, and calorimeter output for calibration.

A standard Gaussian beam geometry of diameter $\sim 5 \mathrm{~mm}$ is generated by the laser system. The spatial distribution is examined by scanning the beam in the

*NAWCWD - Naval Air Warfare Center Weapons Division. 
$x / y$ locations as part of the calibration process to map the highest thermal flux in the beam that is reported. A Vatel, asymptotic calorimeter, placed at the sample location is used to set the thermal flux level. The laser is pulsed a sufficient number of times to ensure the flux level. Calibration of the energy source remains one of the largest variables of the radiant experiment. The average variation in thermal flux calibration is about $4 \%$, but can range as high as $6 \%$ at some energy levels. The usable energy range for this experiment is from 21 to $12,553 \mathrm{~W} / \mathrm{cm}^{2}$ (5 to $\left.3000 \mathrm{cal} /\left(\mathrm{cm}^{2} \mathrm{~s}\right)\right)$. An incident thermal flux level is usually selected that is approximately in the range of the thermal flux delivered by a solid rocket motor ignition system $\left(105-837 \mathrm{~W} / \mathrm{cm}^{2}\right)$. Laser pulse lengths are established using a high response infrared (IR) sensor. Through this measurement, $1 \%$ of the beam is directed into the sensor and the pulse width is adjusted accordingly. Studies have shown that laser stability is reached after a 3-millisecond rise time; thus, the application of a chopper wheel will attenuate the initial portion of the laser beam. It has been found that for exposure times longer than $25 \mathrm{~ms}$, the laser rise time has little or no contribution to either FL or complete ignition and can be ignored.

A minimum of 17 samples were required to determine the propellant ignitability at a given flux level. The individual sample (as seen in Fig. 2) was $6 \mathrm{~mm}$ in diameter and at least $6 \mathrm{~mm}$ in length to allow a sufficient thickness of material to prevent total pyrolysis at long exposure times. The first gasification (FL) line was the average of the photodiode measurements. Complete ignition (GNG), the second line, was determined by means of a Bruceton method of testing and represent the $50 \%$ probability point for ignition. No inhibition of the lateral sample surfaces was used in this study, since the sample fits flush into a steel holder (also visible in Fig. 2). It is recognized that for thermal flux levels less than $10 \mathrm{~W} / \mathrm{cm}^{2}$, heat loss to the steel walls of the sample holder may become an issue.

The burning rates reported in this paper were measured using a cinephotographic technique (window bomb) which has been described elsewhere [5].

\section{SAMPLES}

Ammonium perchlorate is the major oxidizer in most tactical rocket motor formulations. It is also a monopropellant that will self-deflagrate at pressures greater than $2 \mathrm{MPa}$. Other investigators have attributed AP-based propellant ignitability (FL) to the irreversible AP gas-phase decomposition [6, 7]. Therefore, it was thought that the ignitability of the neat material should also be investigated. Pressed AP pellets were used to obtain limited ignitability data for the neat compound. Samples of production grade and ultrapure AP nominally $200 \mu \mathrm{m}$ in diameter were pressed as described in [8]. The pellets were $6.4 \mathrm{~mm}$ in diameter and $9.5 \mathrm{~mm}$ in length. 
Table 1 Nonmetallized propellant formulations

\begin{tabular}{lcccccc}
\hline \multirow{2}{*}{ Ingredients } & \multicolumn{7}{c}{$\%$ (wt.) } \\
\cline { 2 - 7 } & AS12 & AS17 & AS21 & RS & PCP & GAP \\
\hline HTPB/DOA/DDI & 12 & 17 & 21 & 13 & 17 & \\
PCP/DDI & & & & & & 19 \\
GAP/Hylene & & & & & & \\
AP (C/F) & $87.5(1.9)$ & $82.5(1.9)$ & $78.5(1.9)$ & $82(2.3)$ & $82.5(1.9)$ & $81.0(1.5)$ \\
Nitramine & & & & 4.0 & & \\
Ballistic modifier & 0.5 & 0.5 & 0.5 & 1.0 & 0.5 & \\
\hline
\end{tabular}

Table 2 Propellant A-C formulations

\begin{tabular}{lccc}
\hline \multirow{2}{*}{ Ingredients } & \multicolumn{3}{c}{$\%$ (wt.) } \\
\cline { 2 - 4 } & Propellant A & Propellant B & Propellant C \\
\hline $\mathrm{R} 45 / \mathrm{DOS} / \mathrm{IPDI}$ & 10.0 & 10.0 & 10.0 \\
$\mathrm{Al}(29 \mu \mathrm{m})$ & 20.0 & 20.0 & 20.0 \\
$\mathrm{AP}(400 \mu \mathrm{m})$ & - & 50.0 & \\
$\mathrm{AP}(200 \mu \mathrm{m})$ & 50.0 & & 50.0 \\
$\mathrm{AP}(20 \mu \mathrm{m})$ & 20.0 & 20.0 & 20.0 \\
$\mathrm{Fe}_{2} \mathrm{O}_{3}$ & & & 1.2 \\
\hline
\end{tabular}

The ignitability data for a variety of propellants were examined for this paper. The propellants were all formulated with AP as the major oxidizer. They represent both metallized and nonmetallized formulations. They also vary by binder type, particle size of the fuel and oxidizer, and in the $\mathrm{C} / \mathrm{F}$ of the oxidizer particles. The propellants used in this investigation were grouped into several general categories composed of both nonmetallized and metallized formulations.

Six nonmetallized, reduced-smoke propellants that were investigated in this study are listed in Table 1 . Three propellants, AS12, AS17, and AS21, represent a family of hydroxyl-terminated polybutadiene (HTPB) propellants with varying oxidizer levels. In this series of propellants, the $\mathrm{C} / \mathrm{F}$ of $\mathrm{AP}$ was held constant. In the propellant $\mathrm{RS}$, nitramine replaced $4 \%$ (wt.) of the AP and the $\mathrm{C} / \mathrm{F}$ was maintained. Two formulations, hydroxy-terminated polycaprolactone (PCP) and glycidyl azide polymer (GAP), are included in which the HTPB binder system was replaced with PCP and GAP, respectively.

The three metallized propellants listed in Table 2 were formulated with dioctyl sebacate (DOS) as plasticizer and isophrone diisocyanate (IPDI) cured [9]. Propellants A, B, and C were formulated with $90 \%$ (wt.) solids. Propellants A and B differ only in the particle size of the coarse fraction of AP 
Table 3 Propellant $\mathrm{W}-\mathrm{Z}$ formulations

\begin{tabular}{lcccc}
\hline \multirow{2}{*}{ Ingredients } & \multicolumn{4}{c}{$\%($ wt.) } \\
\cline { 2 - 5 } & Propellant W & Propellant X & Propellant Y & Propellant Z \\
\hline R45/DOA/IPDI & 12.0 & 12.0 & 12.0 & 12.0 \\
\hline Al & $20(\mathrm{H} 15)$ & $6.67(\mathrm{H} 5)$ & $20(\mathrm{H} 60)$ & $20(95)$ \\
& & $13.33(\mathrm{H} 15)$ & & 33.0 \\
\hline AP $(11 \mu \mathrm{m})$ & 33.0 & 33.0 & 33.0 & 35.0 \\
\hline AP $(90 \mu \mathrm{m})$ & 35.0 & 35.0 & 35.0 & \\
\hline
\end{tabular}

Table 4 Metallized propellants with PCP binder

\begin{tabular}{|c|c|c|}
\hline \multirow[b]{2}{*}{ Ingredients } & \multicolumn{2}{|c|}{$\%$ (wt.) } \\
\hline & TriA & TriB \\
\hline${\mathrm{PCP} / \mathrm{BTTN}^{*} / \mathrm{TMETN}^{\dagger}}$ & 23.0 & 23.0 \\
\hline $\mathrm{Al}$ & $20.0(\mathrm{H} 15)$ & $\begin{array}{l}15.0(\mathrm{H} 15) \\
5.0(\mathrm{ALEX})\end{array}$ \\
\hline AP (trimodal, 200, 90, $11 \mu \mathrm{m}$ ) & 57.0 & 57.0 \\
\hline
\end{tabular}

(200 vs. $400 \mu \mathrm{m}$ ), and Propellant $\mathrm{C}$ differs from Propellant A by the presence of $\mathrm{Fe}_{2} \mathrm{O}_{3}$, as the burning rate catalyst. The catalyst replaced a portion of the coarse AP fraction.

The four metallized HTPB formulations (propellants W, X, Y, and Z), listed in Table 3, were used to examine the role of particle size to the metal fuel on ignitability. Two additional propellants, TriA and TriB [10], listed in Table 4, examined the effect of adding a small amount of ALEX ${ }^{\circledR}$ to the formulation.

Three metallized propellants listed in Table 5 were formulated with iron oxide as a ballistic modifier. This differs from Propellant C in that IDP replaced both DOS in the CAP propellant. The formulation was further modified with the addition of an inert additive (CAP + inert) [11]. The third propellant listed in Table 6 was formulated with a polybutadiene acrylic acid acrylonitrile (PBAN) binder system.

Three additional propellants, formulated with either all coarse AP or a large coarse AP fraction and reduced solids loading, B1, B2, and B3, are listed in Table 6. Propellant B1 is formulated with a mix of 200 and $400 \mu \mathrm{m} \mathrm{AP}$ in a polyurethane (PU) binder system. The HTPB binder system of Propellants $\mathrm{B} 2$ and B3 has diphenylmethane diisocynate (DDI) as plasticizer in contrast to the other metallized HTPB propellants listed above. The coarse fraction of Propellant B3 is composed of all 400-micron AP. 
Table 5 Metallized propellants with iron oxide burning rate modifier

\begin{tabular}{lccc}
\hline \multirow{2}{*}{ Ingredients } & \multicolumn{3}{c}{$\%$ (wt.) } \\
\cline { 2 - 4 } & CAP & CAP + Inert & PBAN \\
\hline $\mathrm{R} 45 /$ IDP $^{*} /$ IPDI & 11.1 & 11.1 & \\
$\mathrm{HP} /$ Epoxy & & & 14 \\
$\mathrm{Al}$ & 20 & 20 & 16 \\
$\mathrm{AP}(200 \mu \mathrm{m})$ & 50 & & 49 \\
$\mathrm{AP}(20 \mu \mathrm{m})$ & 18 & & 21 \\
$\mathrm{Fe}_{2} \mathrm{O}_{3}$ & 0.9 & 0.9 & 0.3 \\
Inert & & 5.0 & \\
\hline *IDP - isodecyl pelargonete. & &
\end{tabular}

Table 6 "Coarse" AP propellant formulations

\begin{tabular}{lccc}
\hline \multirow{2}{*}{ Ingredients } & \multicolumn{3}{c}{$\%$ (wt.) } \\
\cline { 2 - 4 } & $\mathrm{B} 1$ & $\mathrm{~B} 2$ & $\mathrm{~B} 3$ \\
\hline $\mathrm{PPG}^{*} / \mathrm{TDI}^{\dagger}$ & 20.0 & 14.8 & 13.5 \\
$\mathrm{R} 45 / \mathrm{DDI}$ & & $57.7(400+200 \mu \mathrm{m})$ & $55(400 \mu \mathrm{m})$ \\
$\mathrm{AP}($ coarse $)$ & $61.0(400+200 \mu \mathrm{m})$ & 6.5 & 14.0 \\
$\mathrm{AP}(20 \mu \mathrm{m})$ & & 20.0 & 17.5 \\
$\mathrm{Al}$ & 19.0 & & \\
\hline${ }^{*} \mathrm{PPG}$ - polypropylene glycol. & & \\
${ }^{\dagger} \mathrm{TDI}$ - toluene diisocyanate. &
\end{tabular}

\section{RESULTS}

Ideally, for a study of this type, a suite of propellants should have been formulated to be systematically varied with respect to all of the elements presented to the propellant formulator. In reality, this was not possible. The formulations in this paper have been studied for a number of reasons and represent a large enough body of data from which some conclusions can be made; however, there remain areas where further investigation in a closely controlled environment is warranted.

\section{$5.1 \quad$ Neat Ammonium Perchlorate}

Ammonium perchlorate constitutes the largest component by weight of the propellant samples examined in this study. The high purity oxidizer will burn as a monopropellant at pressures greater than about $2 \mathrm{MPa}$ (300 psia). Production grade AP deflagration limits are much higher $[12,13]$. Limited ignitability stud- 
ies of both production and high purity AP were performed in order to observe and gain insight into the contribution of the neat materials.

Production grade AP pellets would not ignite at pressures of $3.45 \mathrm{MPa}$ (500 psia) at flux levels up to $418 \mathrm{~W} / \mathrm{cm}^{2}\left(100 \mathrm{cal} /\left(\mathrm{cm}^{2} \mathrm{~s}\right)\right)$. Ignitability data for ultrapure AP pellets are plotted in Fig. 4 at two flux levels and temperatures of 25 and $100{ }^{\circ} \mathrm{C}$. A 24 percent decrease in the time to ignition was seen in samples that were preheated to $100{ }^{\circ} \mathrm{C}$. The times be-

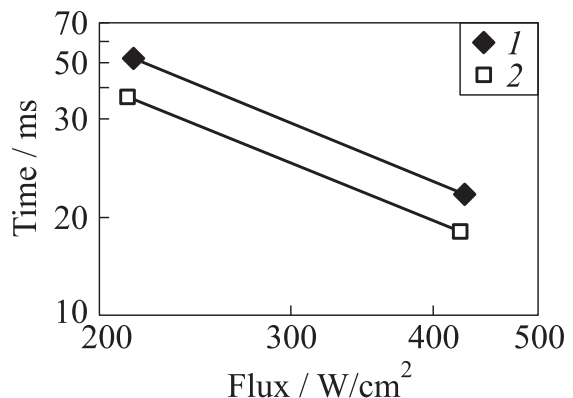

Figure 4 Ignitability of ultrapure AP: 1 - AP $25{ }^{\circ} \mathrm{C}-\mathrm{GNG}$; and $2-\mathrm{AP}$ $100{ }^{\circ} \mathrm{C}-\mathrm{GNG}$ tween first gasification (FL) and complete ignition (GNG) were equivalent at the conditions where reliable data could be obtained. The slope of both of the test conditions is -1.4 [14].

\subsection{Pressure and Flux}

The effect of increasing incident flux on propellant ignitability is illustrated with the PBAN propellant in Fig. 5 at $0.09 \mathrm{MPa}(1 \mathrm{~atm})$. At relatively low energy levels, the time to first gasification (FL) and complete ignition (GNG) are essentially the same. As the flux increases, the time between FL and GNG increases as do the differences between the two propellants. Much of the earlier propellant ignition data were generated in the lower flux regions where there is little or no difference between FL and GNG. As the experiments have been performed at higher thermal flux levels, the distinction between the two regimes is more definite.

The effect of pressure on propellant ignitability is illustrated with a noncatalyzed $\mathrm{AP} / \mathrm{HT} / \mathrm{Al}$ propellant $\mathrm{B} 3$ in Fig. 6 . The sample was tested at pressures from 0.172 to $1.4 \mathrm{MPa}$ (25 to $200 \mathrm{psia}$ ). The effect of pressure on the first gasification (FL) of the propellant is relatively small, while the effect on complete ignition is very large, particularly at the higher flux levels. For this sample, as the pressure increases, the times to FL decrease as the thermal flux increased. The average slope of the FL lines was -2.1 . The long times to complete ignition (GNG) observed at $0.172 \mathrm{MPa}(25 \mathrm{psia})$ indicate over driven ignition at the higher flux levels [15].

\subsection{Solids Loading}

The effect of solids loading on ignitability is illustrated in the plot of nonmetallized propellants AS12, AS17, and AS21 in Fig. 7. The samples were tested at 


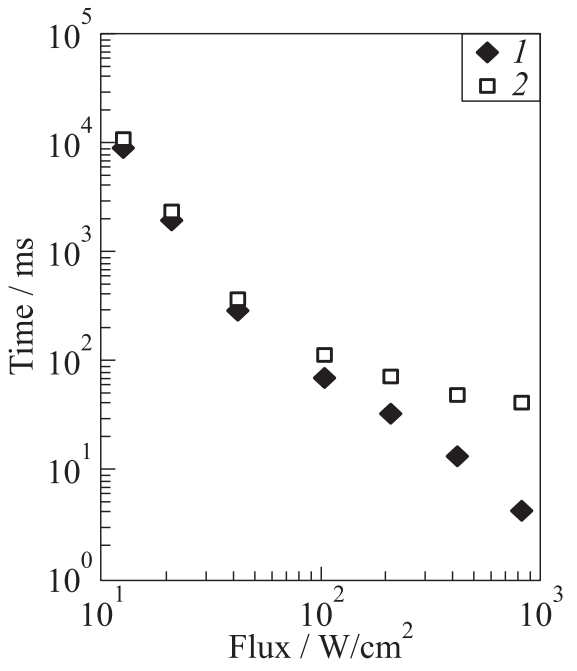

Figure 5 Effect of incident flux levels on propellant ignitability: $1-\mathrm{FL}$; and 2 - GNG

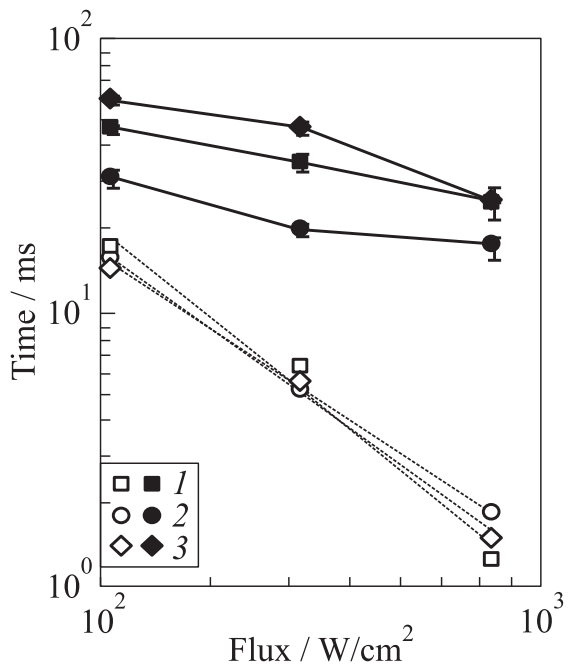

Figure 7 Effect of solids loading on propellant ignitability. Empty signs refer to FL and black signs refer to GNG: $1-$ $12 \%$ (wt.) HTPB; $2-17 \%$ (wt.) HTPB; and $3-21 \%$ (wt.) HTPB

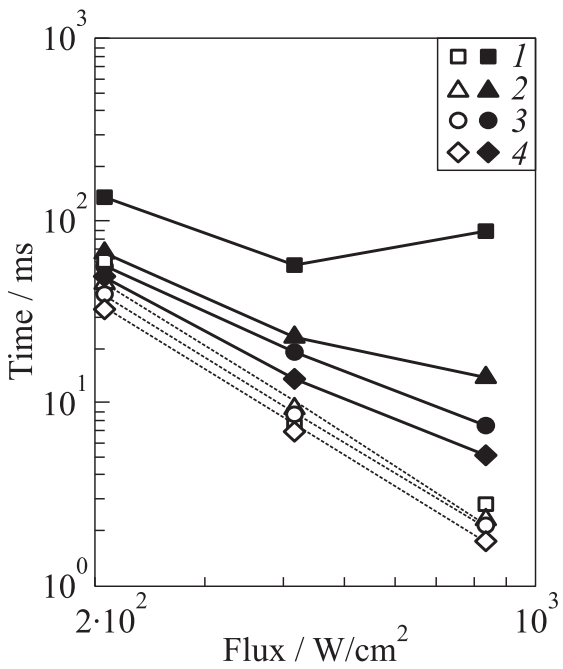

Figure 6 Pressure and flux effects on propellant ignitability. Empty signs refer to FL and black signs refer to GNG: 1 $0.172 \mathrm{MPa} ; 2-0.345 ; 3-0.69$; and $4-1.4 \mathrm{MPa}$

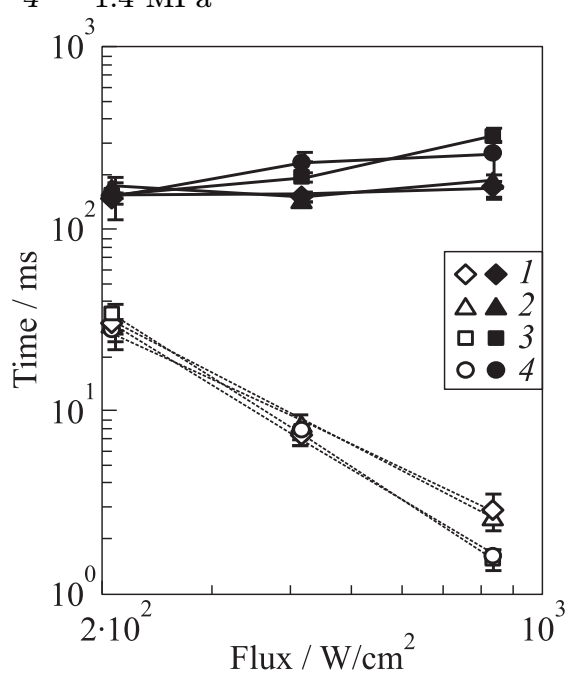

Figure 8 Effect of aluminum particle size on HTPB/AP propellant ignitability. Empty signs refer to FL and black signs refer to GNG: $1-\mathrm{H} 15 ; 2-\mathrm{H} 5 / 15 ; 3-$ H60; and $4-\mathrm{H} 95$ 
$0.09 \mathrm{MPa}(1 \mathrm{~atm})$. It can be seen that while first gasification (FL) shows no significant changes with loading, the time to complete ignition (GNG) becomes shorter as the weight percent of oxidizer increases.

\subsection{Metal}

Ignitability data for a series of AP/HTPB propellants (W, X, Y, and Z) formulated with 20 weight percent aluminum of varying particle sizes are plotted in Fig. 8. There is a very small difference in both first gasification and complete ignition for the propellants formulated with the H60 and H95 aluminum. The propellants formulated with the coarser aluminum gasify earlier but take longer to ignite at these conditions. The slopes of the FL lines were -2.22 and -2.05 , respectively, for the samples formulated with $\mathrm{H} 60$ and H95. The slopes of the FL lines were -1.65 and -1.78 , respectively, for the propellants formulated with H15 and H5.

The effects of the aluminum particle size on the ignitability of a $\mathrm{PCP} / \mathrm{AP}$ propellant formulation were investigated in a propellant formulated with 20 weight percent $\mathrm{H} 15$ (TriA), and in an additional formulation where $5 \%$ (wt.) was replaced with ALEX (TriB). These data are plotted in Fig. 9. As seen in the

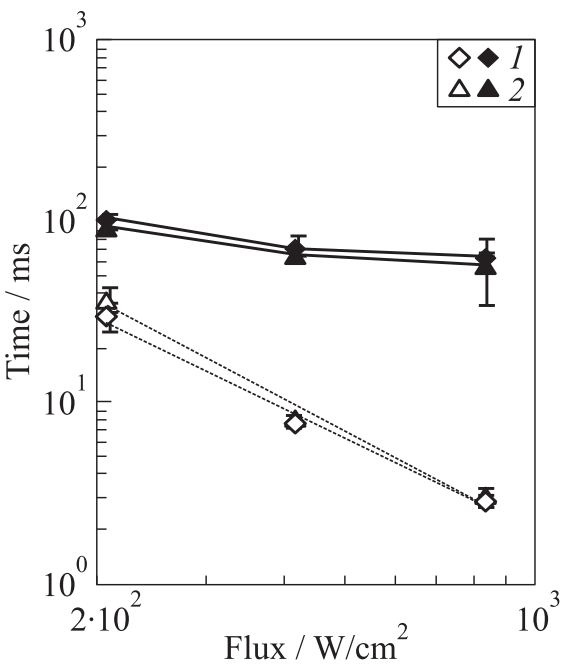

Figure $9 \mathrm{H} 15$ and $\mathrm{H} 15$ plus 5 weight percent ALEX in AP/PCP propellant. Empty signs refer to FL and black signs refer to GNG: $1-\mathrm{H} 15$; and $2-$ H15Alex

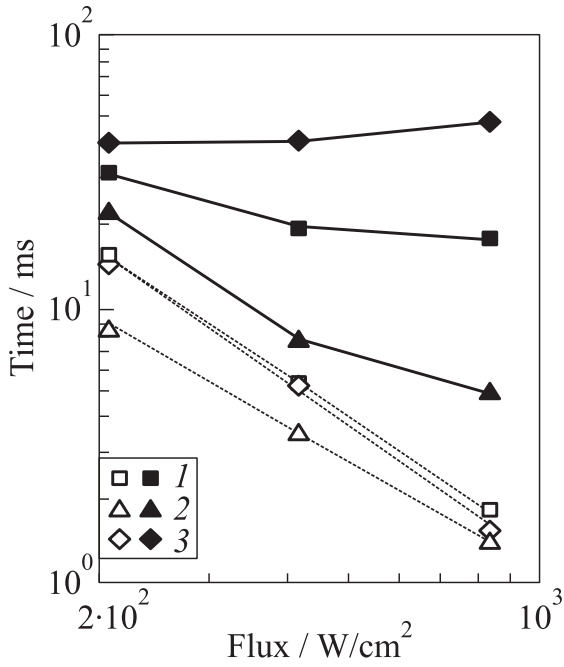

Figure 10 Binder effects on ignitability of a nonmetallized formulation. Empty signs refer to FL and black signs refer to GNG: $1-17 \%$ (wt.) HTPB; $2-$ $19 \%$ (wt.) GAP; and 3-17\%(wt.) PCP 
study with HTPB, the addition of $5 \%$ (wt.) fine aluminum did not significantly alter the characteristics of ignition.

\subsection{Binder Type}

The effect of the binder type on propellant ignitability is better illustrated in the plot of nonmetallized propellants of Fig. 10. In this case, the AP particle size and $\mathrm{C} / \mathrm{F}$ ratios were maintained. There is a small decrease in solids loading for the GAP-based sample. In this figure, the energetic GAP formulation was easiest to both gasify and ignite, while in the PCP and HTPB propellants, gasification was comparable with the HTPB formulation reaching complete ignition roughly two times faster than the PCP-based sample [16].

A comparison of two propellants formulated with $\mathrm{H} 15$ aluminum, W, and TriA, is made in Fig. 11. It should be noted that these two formulations differ not only in binder type and solids loading, but they also differ in the AP particle size and $\mathrm{C} / \mathrm{F}$ ratios. Based on the above observations, one might expect the TriA propellant to be slower; however, the nitroplasticizer, which makes up nearly $17 \%$ (wt.) of the formulation, dominates the ignition process in the TriA propellant, while the first gasification (FL) remains unaffected by the addition of

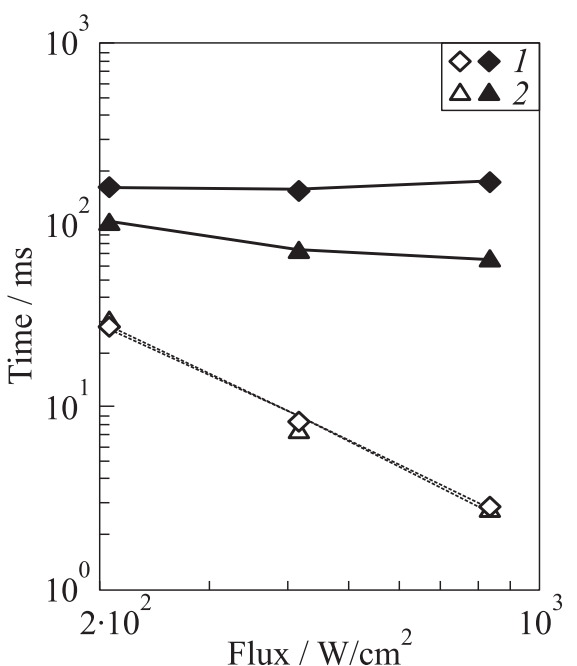

Figure 11 A comparison of $\mathrm{W}$ and TriA propellants with H15 aluminum. Empty signs refer to FL and black signs refer to GNG: $1-\mathrm{HT}$ with $\mathrm{H} 15$; and $2-\mathrm{PCP}$ with $\mathrm{H} 15$

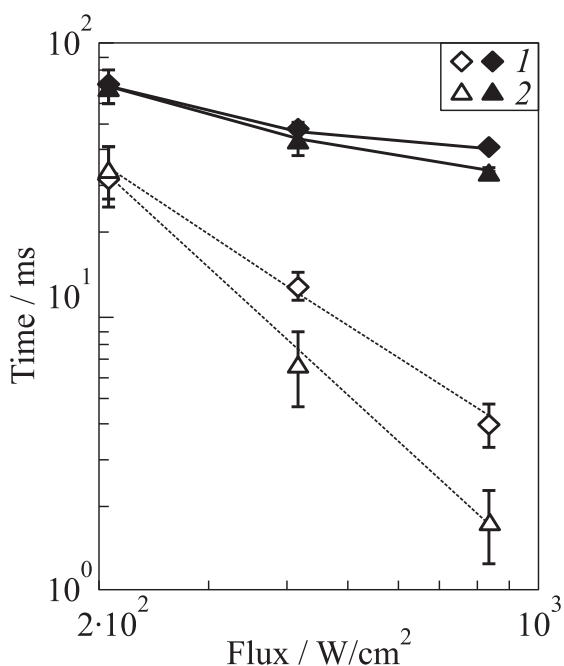

Figure 12 A comparison of PBAN and HTPB based propellant ignitability at $0.09 \mathrm{MPa}(1 \mathrm{~atm})$. Empty signs refer to FL and black signs refer to GNG: $1-$ PBAN1; and $2-\mathrm{CAP}$ 


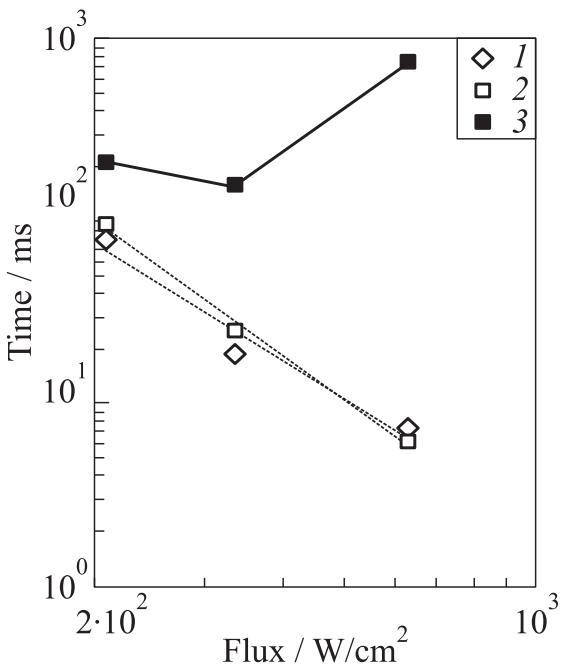

Figure 13 Ignitability data for $\mathrm{PU}$ and HTPB propellant at $0.09 \mathrm{MPa}(1 \mathrm{~atm})$ : $1-\mathrm{B} 1(\mathrm{FL}) ; 2-\mathrm{B} 2(\mathrm{FL}) ;$ and $3-\mathrm{B} 2$ (GNG)

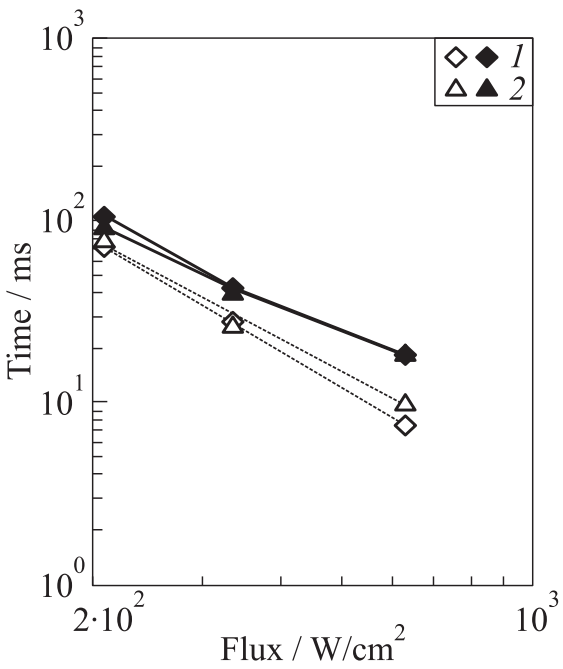

Figure 14 Effect of pressure on PU and HTPB propellant ignition at $0.69 \mathrm{MPa}$ (100 psia). Empty signs refer to FL and black signs refer to GNG: $1-\mathrm{B} 1$; and $2-\mathrm{B} 2$

either plasticizer or the trimodal AP. A comparison of PBAN and HTPB binders on ignitability (0.09-megapascal pressure) is made in Fig. 12 where the metallized CAP is plotted with PBAN. The two aluminized propellants have similar AP amounts and types, and both have iron oxide as a burning rate modifier. In this case, it appears that the two different binder systems do not have a strong influence on the ignition behavior.

In contrast, Fig. 13 compares the ignitability of two metallized formulations, B1 and B2, based on PU and HTPB at $0.09 \mathrm{MPa}(1 \mathrm{~atm})$. In this case, the ignitability differed for the two materials in that the PU-based formulation did not reach complete ignition (GNG) for times up to $1 \mathrm{~s}$ at ambient pressure. In contrast, the HTPB-based propellant, B1, ignited at ambient pressure but was overdriven at $\sim 627 \mathrm{~W} / \mathrm{cm}^{2}$. The differences seen in the ignitability of the two propellants disappeared when the test pressure was increased to $0.69 \mathrm{MPa}$ (100 psia) as illustrated in Fig. 14.

\subsection{Additives}

The effect of the addition of the burning rate modifier (iron oxide) on HTPB propellant ignitability is illustrated (at $0.69 \mathrm{MPa}$ ) in the plot of Propellants A and $\mathrm{C}$ in Fig. 15. The slope of the FL is -1.86 for Propellant A and -1.98 for 


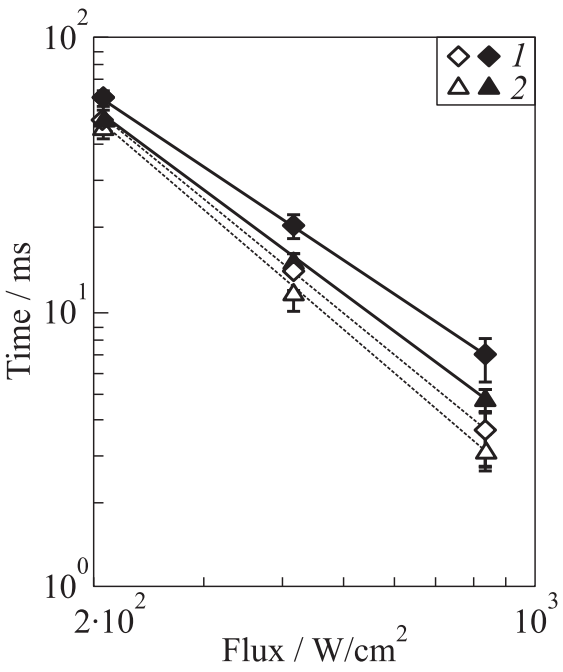

Figure 15 The effect of iron oxide on propellant ignitability at $0.69 \mathrm{MPa}$. Empty signs refer to FL and black signs refer to GNG: 1 - Propellant A; and 2Propellant C

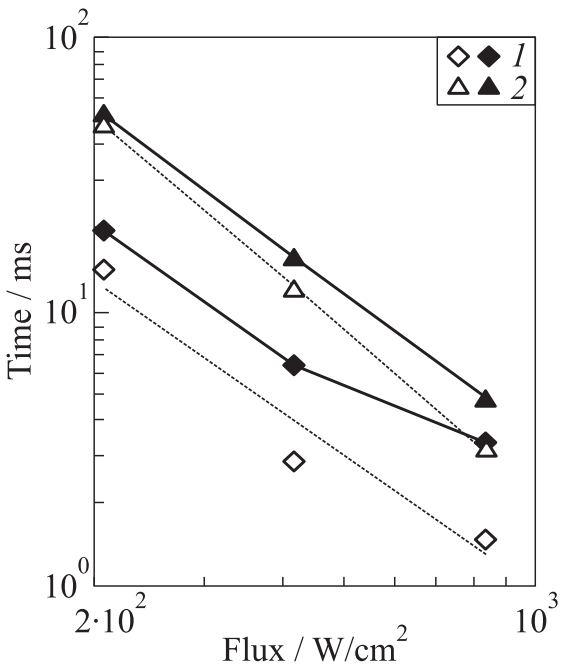

Figure 16 Ignitability of CAP (1) and Propellant C (2) at $0.69 \mathrm{MPa}$. Empty signs refer to FL and black signs refer to GNG

Propellant C. Based on the current observations, one would expect the ignitability of CAP and Propellant $\mathrm{C}$ to be very similar. The two propellants have the same AP particle size and $\mathrm{C} / \mathrm{F}$ ratios and are iron oxide catalyzed; however, the ignitability of the two propellants is not comparable for $0.69 \mathrm{MPa}$, as seen in Fig. 16. The only major difference in the two propellants is that Propellant $\mathrm{C}$ was formulated with DOS while CAP was formulated with dioctyladipate (DOA).

A second formulation of CAP was made by substituting $5 \%$ (wt.) of a dense inert additive for the $\mathrm{AP}$. The $\mathrm{C} / \mathrm{F}$ ratio of $\mathrm{AP}$ was maintained. The effect of the addition of what is essentially a coolant to the formulation is shown in the plot of Fig. 17 at $0.09 \mathrm{MPa}$ (1 atm), where the largest difference is seen in the complete ignition (GNG). The effect of the inert additive on the low-pressure burning rates is plotted in Fig. 18. The low-pressure burning rate of the CAP propellant is higher than that containing the inert additive also seen in the ease of ignition. The relationship between the ease of ignition and the propellant burning rate is a common observation.

Figure 19 shows a comparison of two nonmetallized propellants formulated at 12 weight percent HTPB. The ignitability data do not appear to be significantly altered by the addition of nitramine at $4 \%$ (wt.). This has also been observed in metallized propellants containing small amounts of nitramine. 


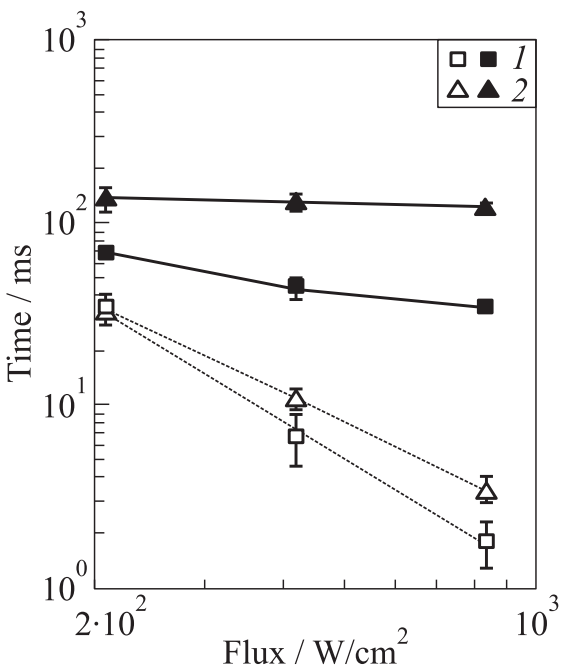

Figure 17 The effect of inert additive on ignition of CAP propellant. Empty signs refer to FL and black signs refer to GNG: 1 - CAP; and 2-CAP + Inert

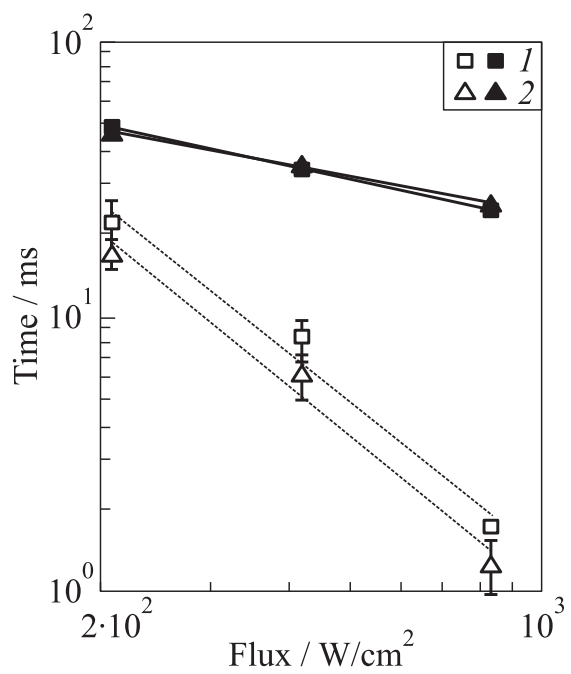

Figure 19 The effect of nitramine on nonmetallized propellant ignition. Empty signs refer to FL and black signs refer to GNG: $1-\mathrm{RS}$; and $2-\mathrm{AS} 12$

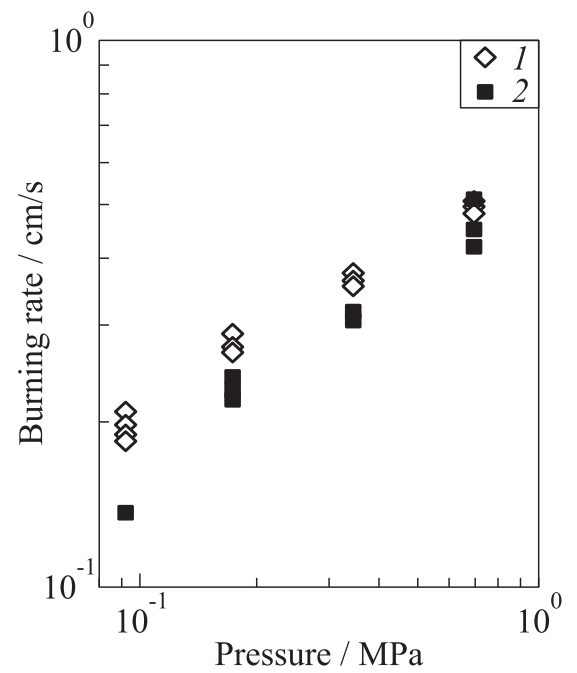

Figure 18 The effect of inert additive on low-pressure burning rate of CAP propellant: $1-\mathrm{CAP}$; and $2-\mathrm{CAP}+$ Inert

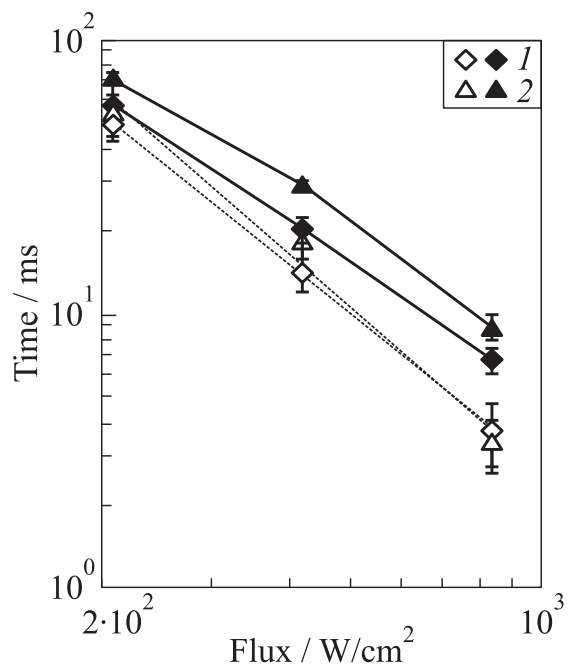

Figure 20 Effect of coarse AP on propellant ignitability at $0.69 \mathrm{MPa}$. Empty signs refer to FL and black signs refer to GNG: $1-$ Propellant A; and $2-$ Propellant B 


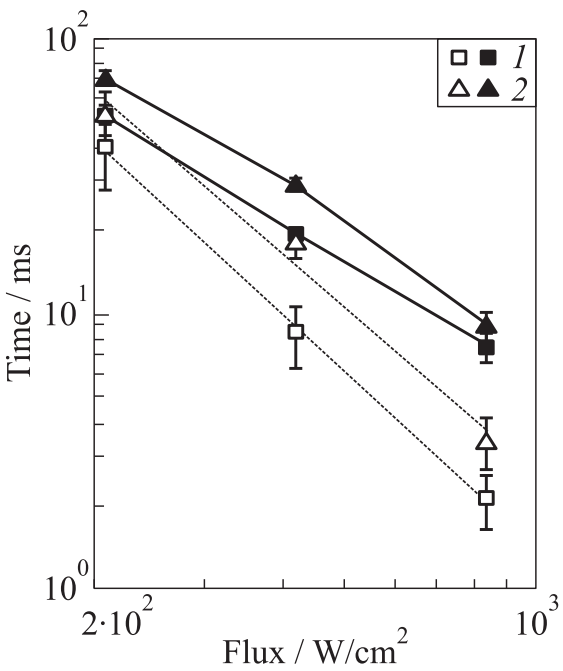

Figure 21 A comparison of propellants formulated with 400-micron AP. Empty signs refer to FL and black signs refer to GNG: 1 - Propellant B3; and 2 - Propellant B

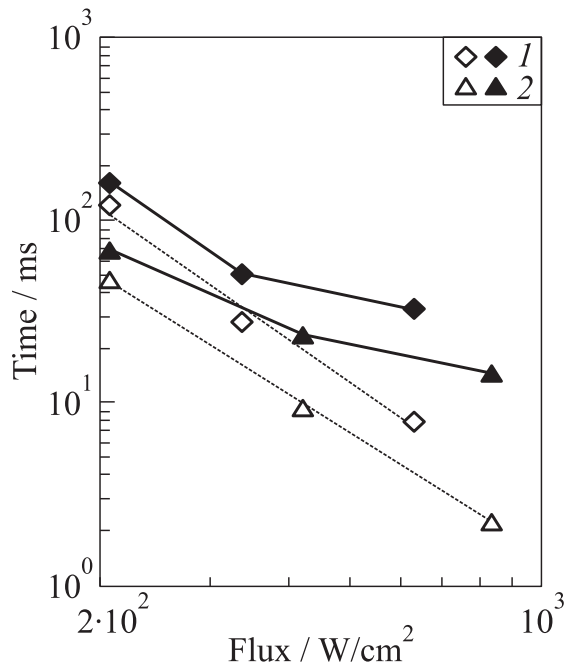

Figure 22 Effect of coarse to fine ratio on propellant ignitability. Empty signs refer to FL and black signs refer to GNG: 1 - Propellant B2; and 2 - Propellant B3

\subsection{Particle Size}

The effect of particle size on propellant ignitability is illustrated in the plot of Propellants A and B in Fig. 20, where 400-micron AP replaces the 200-micron in the coarse fraction. One would expect the ignitability of Propellants B and B3 to be very similar, as they are both formulated with 400-micron AP in the coarse fraction. The ignitability of the two formulations is compared in Fig. 21. Additionally, the $\mathrm{C} / \mathrm{F}$ ratio of AP is slightly higher in Propellant B3, but, as seen earlier with the DOS/DOA comparison, the propellant formulated with DOS is more difficult to ignite than that containing DDI.

In the case of Propellants $\mathrm{B} 2$ and $\mathrm{B} 3$, the effect of the $\mathrm{C} / \mathrm{F}$ ratio of $\mathrm{AP}$ is illustrated in Fig. 22. The $\mathrm{C} / \mathrm{F}$ ratio is about 9 in the $\mathrm{B} 2$ propellant and 4 in B3. Both the time to first gasification (FL) and complete ignition (GNG) are shorter in the propellant with the reduced $\mathrm{C} / \mathrm{F}$ ratio, even though it contains a larger diameter coarse fraction.

\section{SUMMARY AND CONCLUDING REMARKS}

Neat AP is difficult to ignite due to its high pressure deflagration limit [12]. This is especially true for the production grade AP, which would not ignite reliably 


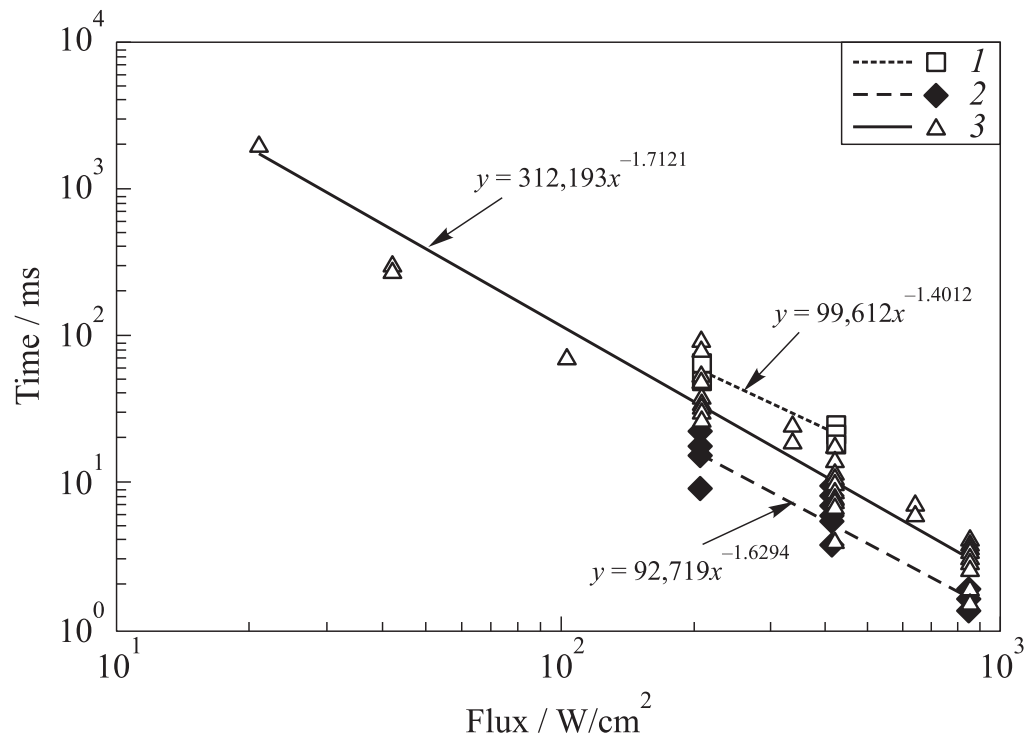

Figure 23 Summary of the times to first gasification: $1-$ AP-GNG; $2-$ FL - no metal; and 3 - FL-metal

under the conditions of the test. Times to complete ignition were decreased about $25 \%$ with the increase in initial sample temperature. It should be noted that the addition of even small amounts of fuel, for example, from handling, will markedly change the ease of ignition.

As the external radiant flux increases, the times to first gasification decrease. These times remain relatively independent of changes in pressure. The times to complete ignition, in contrast, are sensitive to pressure with their decrease to that of the first gasification time as pressure increased. These data suggest that the initial reactions occurring on the surface of the propellant are dominated in the condensed phase, with the complete ignition being driven by gas-phase reactions.

At incident flux levels of less than $200 \mathrm{~W} / \mathrm{cm}^{2}$, first gasification and complete ignition occur simultaneously. Times to first gasification and complete ignition tend to diverge at the flux levels and lower pressures. Lower pressure conditions were found to be the best to observe the effects of formulation variables on the ignition process.

The times to first gasification are summarized and compared to the neat AP ignition in Fig. 23 for all of the samples described in this paper. The results fall into three general groups. The times to ignition (FL/GNG) are equal for the neat $\mathrm{AP}$ at the conditions tested, and are the longest with an average slope 
of -1.4. The nonmetallized formulations have the shortest times to FL, with a slope of -1.6 . The metallized formulations fall between the neat AP and the nonmetallized formulations with a slope of -1.7 .

Changes in the solids loading (AS12, AS17, and AS21) showed no changes in the times to first gasification, but complete ignition times decreased as solids loading increased.

The addition of aluminum appears to increase the times to first gasification over those of the nonmetallized formulations. The changes in diameter of the aluminum did not appear to alter either the first gasification or complete ignition times. This was observed for both HTPB and PCP binder systems.

Times to complete ignition decreased with the inclusion of reactive binder systems. In the GAP, HTPB, and PCP nonmetallized formulations, the times to first gasification only decreased slightly with the inclusion of energetic binders in the formulation. The binder effects were observed to decrease and even disappear with the addition of pressures as low as $0.69 \mathrm{MPa}$ (100 psia).

The type of inert plasticizer, DOS, DOA, or DDI, also appears to have an effect on the ignitability process. With the DOS-based system having the longest times to both first gasification and complete ignition, the formation of a melt layer [17] on the propellants formulated with DOA and DDI may contribute to the differences observed in these formulations [18].

The burning rate catalyst, $\mathrm{Fe}_{2} \mathrm{O}_{3}$, also decreased the times to complete ignition, while small additions of nitramine did not appear to have a strong effect on the ignitability in the samples tested. The addition of the inert additive decreased both the first gasification and complete ignition reflecting a contribution of the difference in surface temperature.

Increasing the coarse particle size of the AP from 200 to $400 \mu \mathrm{m}$ increased the times to complete ignition with no change in the time to first gasification. The greater effect was observed in the propellants formulated with changes in the $\mathrm{C} / \mathrm{F}$ ratio of AP. Times to both first gasification and complete ignition increased as $\mathrm{C} / \mathrm{F}$ increased.

The metallized first gasification data plotted in Figs. 5 and 23 are compared to similar data of a number of investigators in Fig. 24 [4, 7, 19]. The propellant tested by Baer and Ryan contained only 2 weight percent aluminum and, as expected, are easier to gasify. It is interesting to note that the data between 40 and $150 \mathrm{~W} / \mathrm{cm}^{2}$ has a lower slope than that generated at either the lower or higher flux regions. Both sets of data (Ref. [19] and this study) used a $\mathrm{CO}_{2}$ as a radiant energy source. Earlier conclusions attributed this low slope region to calibration difficulties; however, it is interesting to note that similar changes in slope were observed in two separate experimental studies. The spread in the CL-FL data is attributed to the formulation variations discussed in this paper.

The ignition data presented in this paper suggest a complex relationship between the propellant binder and solid ingredients that begins with the first gasification (early exothermic behavior) and ends with steady state combustion. 


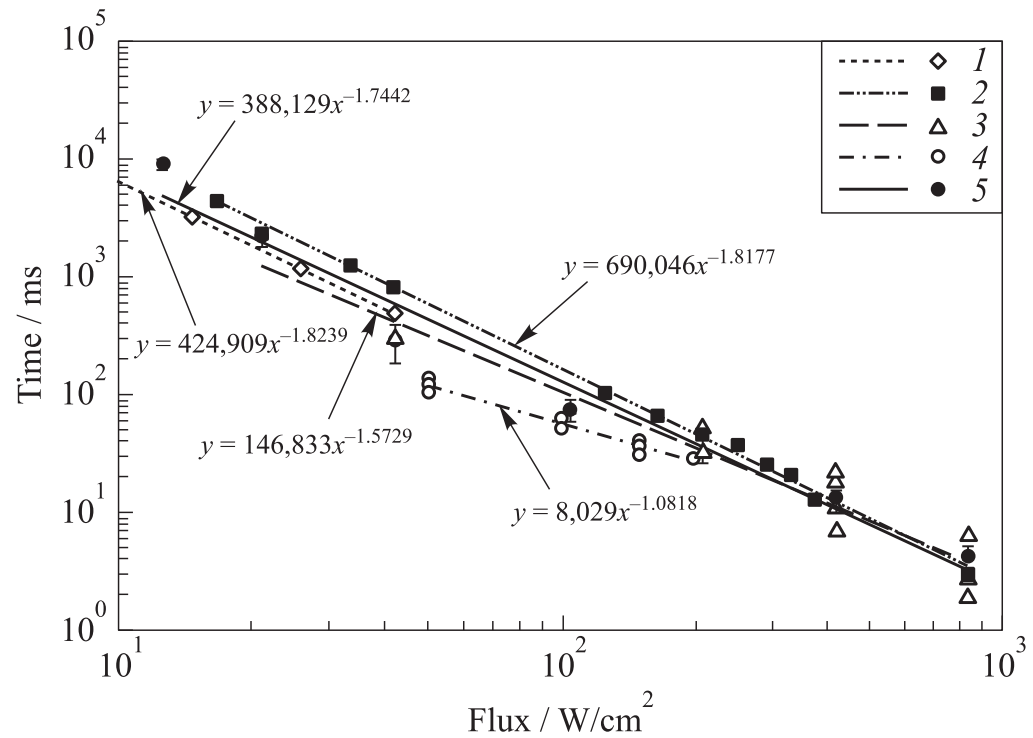

Figure 24 A comparison of ignition data from four different sources: 1 - FL [4]; 2 - FL [7]; 3 - FL (authors' data); 4 - FL [19]; and 5-PBAN (authors' data)

It is often difficult to resolve what appears as additive effects of the various ingredients with respect to the ignition process. These data are presented to support the analytical evaluation of the propellant combustion process and to suggest further studies with systematically controlled propellant formulations.

\section{REFERENCES}

1. Atwood, A., C. Price, and T. Boggs. 1991. Ignitability measurements of solid propellants. 22nd Annual Conference (International) of ICT Proceedings. 44-1-44-15.

2. Caveny, L., and M. Summerfield. 1973. Solid propellant flammability including ignitability and combustion limits. 10th JANNAF Combustion Meeting Proceedings. CPIA Pub. 243. III:133-56.

3. DeLuca, L., L. Caveny, T. Ohlemiller, and M. Summerfield. 1976. Radiative ignition of double-base propellants: I. Some formulation effects. AIAA J. 14(7):940-48.

4. Baer, A., and N. Ryan. 1964. Ignition of composite propellants by low radiant fluxes. AIAA J. 3(5):884-89.

5. Boggs, T., J. Crump, K. Kraeutle, and D. Zurn. 1978. Cinephotomicrography and scanning electron microscopy as used to study solid propellant combustion. In: Experimental diagnostics in combustion of solids. Progress in astronautics and aeronautics ser. 63:20-47. 
6. Inami, S. H., L. McCulley, and H. Wise. 1969. Ignition response of solid propellants to radiation and conduction. Combust. Flame 13(5):531-36.

7. Lengelle, G., A. Bizot, J. Duterque, and J. Amiot. 1991. Ignition of solid propellants. La Recherche Aerospatiale 2:1-20.

8. Atwood, A., T. Boggs, P. Curran, T. Parr, D. Hanson-Parr, and J. Wiknich. 1999. Burning rate of solid propellant ingredients. Part 1: Pressure and initial temperature effects. J. Propul. Power 15(6):738-52.

9. Lee, I., and J. Covino. 1995. Thermal response of AP/HTPB based propellants with varying compositions. 1995 JANNAF Propulsion Systems Hazards Subcommittee Meeting Proceedings. CPIA Pub. 638. II:1-7.

10. Bui, D., A. Atwood, and T. AtienzaMoore. 2004. Effect of aluminum particle size on combustion behavior of aluminized propellants in PCP binder. 35th ICT Conference (International). Karlsruhe, Germany.

11. Atwood, A., N. Zwierzchowski, P. Curran, and J. Braun. 1993. Combustion of propellants containing a high density, inert additive. 30th JANNAF Combustion Subcommittee Meeting.

12. Boggs, T. L., D. E. Zurn, and D. W. Netzer. 1973. Ammonium perchlorate combustion: Effects of sample preparation; ingredient type; and pressure, temperature and acceleration environments. Combust. Sci. Technol. 7(4):177-83.

13. Naval Weapons Center. Response of ammonium perchlorate to thermal and mechanical shock stimuli. 1990. NWC TP 7053, 1 Administration Circle. China Lake, California, 93555, USA.

14. Atwood, A., C. Price, T. Boggs, P. Curran, and N. Zwierzchowski. 1990. Ignition and combustion properties of ammonium perchlorate. 1990 JANNAF Propulsion Systems Hazards Subcommittee Meeting Proceedings. CPIA Pub. 538. I:565-76.

15. Ohlemiller, T., L. Caveny, L. DeLuca, and M. Summerfield. 1972. Dynamic effects on ignitability limits of solid propellants subjected to radiative heating. 14th Symposium (International) on Combustion Proceedings. The Combustion Institute.

16. Boggs, T., A. Atwood, K. Graham, A. Lepie, C. Price, H. Richter, and D. Zurn. 1986. Hazards of solid rocket propellants. Eastern States Combustion Meeting Proceedings. B1-B12.

17. Cohen, N., and J. Hightower. 1992. An explanation for anomalous combustion behavior in composite propellants. 29th JANNAF Combustion Meeting Proceedings. CPIA Pub. 593. 253-73.

18. Atwood, A., P. Curran, C. Price, T. Boggs, and D. Booth. 2000. High pressure burning rate studies of ammonium perchlorate (AP) based propellants. Small Rocket Motors and Gas Generators for Land, Sea and Air Launched Weapons Systems Proceedings. North Atlantic Treaty Organization. RTO-MP-23. 43.1-43.6.

19. Bandera, A., A. Conti, D. Orsini, L. Deluca, B. D'Andrea, K. Ford, P. Curran, and A. Atwood. 2007. Laser ignition studies of composite solid rocket propellants. Workshop (International) on High Energy Materials Performances and Civil Applications. Arcachon, France. Association Aeronautique Astronautique de France. 